\title{
Débora Morato Pinto - Consciência e memória
}

São Paulo: WMF Martins Fontes, 2013

\section{Fernando Aparecido Poiana ${ }^{1}$}

O crescente interesse por textos autobiográficos e pela literatura de testemunho tem trazido à tona questões fundamentais sobre a intersecção entre literatura, história e memória. Como resultado, as fronteiras entre memória e consciência, literatura e história, ou mesmo ficção e realidade são comumente levadas ao seu limite conceitual e, não raro, diluídas consideravelmente. É diante disso que Consciência $e$ memória (2013) constitui bibliografia essencial no tratamento desses assuntos. Escrito por Débora Morato Pinto, doutora em filosofia pela USP e professora do Departamento de Filosofia da UFSCar, o livro propõe uma reflexão conceitualmente rigorosa sobre as relações entre consciência e memória a partir de um recorte metodológico que privilegia o tratamento que filósofos específicos deram à relação entre esses dois conceitos em seus respectivos sistemas de pensamento.

Consciência e memória parte da premissa de que "a cultura do século XX tem uma ligação íntima com a ideia de consciência" (p. 9) para examinar as nuances que esse conceito assumiu no pensamento de diferentes filósofos. Para a autora, o próprio uso corriqueiro de expressões como "tenho consciência das coisas...", "minha consciência me diz..." e "não posso agir contra minha consciência" demonstra que, ao pensar sua relação com ele mesmo e com o mundo, o homem toma como paradigma conceitual essa forma de conhecimento que lhe permite vivenciar, experimentar ou pensar seu mundo interior. Há, portanto, uma crença de que "somos dotados de uma forma de relação muito particular com nosso 'eu' ou nossa 'pessoa'” (p. 9), que "está envolvida numa confiança permanente no fato de que somos dotados de consciência" (p. 9), e cuja posse é comumente relacionada ao fato de “possuirmos algo como um 'mundo' de ideias, sentimentos, desejos e imagens íntimas e privadas, um 'reservatório' secreto de vivências em que podemos mergulhar sempre que tivermos ocasião" (p. 9). Essa imagem do "reservatório" sugere, portanto, a existência de um lastro de

\footnotetext{
${ }^{1}$ Doutorando em teoria e estudos literários na Universidade Estadual Paulista Júlio de Mesquita Filho (UNESP), São José do Rio Preto, SP, Brasil. E-mail: fernando_poiana@ @otmail.com
} 
experiências anteriores que foram acumuladas e que podem ser acessadas por meio de algum mecanismo mnemônico.

Segundo Pinto, a proximidade semântica entre consciência, subjetividade e interioridade faz com que a relação entre consciência e memória seja muitas vezes baseada no "fato de que podemos nos lembrar daquilo que vivemos, aprendemos e conhecemos" (p. 10). O fato de esses termos serem comumente pensados analogamente à autoconsciência, e, por isso, envolverem uma relação racional e interior consigo mesmo também contribui para essa associação. Desse modo, aceitar que o indivíduo seja capaz de se lembrar do que aprendeu e conheceu por meio de suas vivências implica assumir que a sua faculdade de pensar seja sustentada pela sua memória. Nesse sentido, a memória sustenta "a crença de que somos dotados de consciência" (p. 10), o que encontra respaldo "na confiança que adquirimos em nossa capacidade de pensar, de refletir e de organizar nossas ideias" (p. 10). Sendo assim, ao tratar da relação entre consciência e memória a partir da subordinação da primeira à segunda, Pinto aborda a dimensão da duração da consciência e da memória, e introduz a noção de tempo nessa relação conceitual. "Alguém que não pode lembrar do que viveu, viu, ouviu e adquiriu como aprendizado não pode tomar decisões, não exerce sua atividade consciente" (p. 10-11). Não coincidentemente, portanto, o potencial do ser humano para adquirir conhecimento inclui termos como lembrança, reminiscência e esquecimento. Essa inclinação ao conhecimento envolve ainda o que a autora chama de "propensão racional da alma" (p. 11), ancestral grego da noção moderna de consciência. Como Pinto declara, "conhecer, ato supremo da racionalidade ocidental, é, desde a origem do pensamento filosófico grego, intrinsecamente associado à memória" (p. 12). Sendo assim, o conhecimento é subordinado à capacidade do indivíduo de recordar. Pinto afirma que "a relação com a verdade passa, portanto, pelo ato de lembrar-se, de recuperar o esquecido pela lembrança. A verdade, alétheia, é o "não esquecido" (p. 11).

Mas é com a Modernidade que o conceito de consciência passa a ocupar papel essencial na definição do ser humano. De fato, Pinto declara que "ainda somos muito influenciados por valores que, mesmo em crise, continuam a pautar nossas ações e crenças" (p. 17). As respostas para as questões sobre quem é a humanidade moderna 
ou o que a caracteriza passam, portanto, pela "racionalidade objetiva como porto seguro do conhecimento e da ação" (p. 17). A autora é coerente ao defender que é "na filosofia do século XVII que encontramos as raízes de nosso apego à consciência como base e garantia da liberdade individual" (p. 17). Nesse sentido, o pensamento de Descartes é paradigmático, pois "sintetiza exemplarmente a identificação entre razão, conhecimento e consciência" (p. 18). Seu método "refunda o conhecimento, analisando aquilo que aparece à sua consciência" (p. 20). Pinto sugere que Descartes toma a noção de pensamento como categoria central, "de cuja existência estamos mais certos" (p. 20), explora a noção de ideia metonimicamente, como parte e desdobramento do pensamento, para então elaborar sua filosofia da representação. Desse modo, Pinto conclui que o conteúdo do pensar dentro da perspectiva racionalista é constituído a partir das ideias "verdadeiras ou falsas, tomadas como cópias ou decalques mentais da realidade" (p. 21). Nesse sentido, o conhecimento privilegia a capacidade de representar e o próprio pensamento é constitutivo do conhecimento. Descartes condiciona, assim, o sentimento ao pensamento, pois para ele as sensações só existem a partir do momento em que a consciência de sua existência foi criada. Ou seja, a sensação, para o racionalismo, deve existir primeiramente enquanto conceito ou ideia. Diante dessa formulação racionalista, a consciência é "um conjunto de representações, algumas confusas e provisórias, outras claras, distintas e definitivas, base de todas as nossas certezas e fundamento sólido de nossa liberdade" (p. 21). Nesse sentido, a filosofia de Descartes corresponde a um esforço supremo da razão que, por sua vez, leva à certeza de que "somos seres de pensamento, acompanhada de uma profunda desconfiança em relação aos dados que nos chegam através dos sentidos" (p. 18).

A essa confiança na razão do racionalismo de Descartes, Pinto contrapõe a reação empirista de John Locke (1632-1704), George Berkeley (1685-1753) e, sobretudo, David Hume (1711-1776). Hume reconhecia a existência de "uma base psicológica para a consciência, embora refutasse o fundamento inabalável da consciência de si que os racionalistas valorizavam extremamente" (p. 29). Pinto vê em Hume um empirismo radical e original, que toma a observação como "único fundamento sólido para a ciência do homem, da qual dependem todas as outras" (p. 29-30). Ela explica que Hume confere primazia às 
impressões na formação das ideias e concebe a separação entre o ato de pensar e o de sentir como diferença de intensidade. Portanto, é a associação das ideais que produz o conhecimento na perspectiva empirista de Hume, e a consciência surge a partir das impressões e das ideias simples. Ao tratar da consciência e da mente "como feixe de percepções concatenadas" (p. 32), Pinto descortina o mecanismo que sustenta a afirmação de que as ideias "unem-se naturalmente por sua semelhança e por sua contiguidade no tempo e no espaço e pela repetição de sua aparição à mente segundo uma relação de causalidade" (p. 32). Essa noção de contiguidade e repetição introduz, por sua vez, a problemática do hábito enquanto facilitador ou promotor das conexões entre as ideias na imaginação humana. Isso porque, para Hume, a consciência depende diretamente da memória e da imaginação, e não é indecomponível. A consciência "constrói sua relação a si mesma [...] também pela associação, pelo hábito" (Pinto, 2013, p. 33). Nesse sentido, a associação e dependência entre memória, consciência e hábito representa um golpe severo na ideia de identidade pessoal da Modernidade. Para o empirismo de Hume "a constituição do conteúdo de nossa consciência assenta-se na capacidade que temos de estabelecer inferências a partir da repetição e do hábito" (p. 33), e não na existência de um "conjunto de fatos que nos pertencem, constituindo nossa interioridade ou nossa subjetividade" (p. 10). Portanto, a concepção empirista do conhecimento coloca-se em franca oposição à racionalista porque é permeada por "uma consideração da memória como faculdade de representação do passado" (p. 34). Em outros termos, somente "a conjunção constante entre duas ou mais impressões" (p. 34), viabilizada pelo recurso às lembranças, pode conduzir à "formação das ideias e [ao] uso efetivo da ideia de causalidade nos juízos que sustentam nossas ações" (p. 34).

Pinto aprofunda a correlação entre consciência e memória ao tratar da maneira como Henri Bergson (1857-1941) pensa essas duas categorias. Para ele, a consciência é um "corpo organizado e uma história em construção" (p. 46). Bergson defende que, "tomada profundamente, a consciência é memória" (p. 40). Segundo a autora, o bergsonismo opera uma mudança de paradigma ao pensar a consciência como memória não dissociada da vida que o torna original e relevante para o século XX. Nas palavras da autora, “a consciência, 
muito mais do que uma prerrogativa humana cuja essência reside na racionalidade, é uma dimensão de todos os seres vivos e tem mesmo uma presença universal, cosmológica" (p. 38). Desse modo, a consciência para Bergson precede a vida, entendida aqui no sentido do "ser" da metafísica. Para Pinto, ao relacionar o progresso na vida (ou seja, no ser) à ampliação da consciência, Bergson concebe a vida como movimento ou processo, o que ultrapassa a filosofia da representação racionalista. A consciência para Bergson é "pura mudança, e as ideias são produtos derivados de seu progresso no tempo" (p. 38). Pinto complementa que para ele não existem estados de consciência, mas apenas mudanças. A consciência e a memória têm um caráter dinâmico e fluido, pois os "estados de consciência dão-se como progresso de diferentes vivências, mesmo que os tomemos de forma isolada" (p. 42).

A ideia de consciência como memória de Bergson influenciou profundamente Gilles Deleuze (1925-1995), principalmente "a compreensão de que a totalidade de nossa experiência vivida conserva-se e repete-se incessantemente em milhares de planos de consciência distintos" (p. 53). Deleuze explorou, em sua filosofia da diferença e da repetição, a condição de que o passado "tem um peso ontológico considerável naquilo que se apresenta como a experiência real" (p. 54). Nesse sentido, Bergson e Deleuze se aproximam, porque reconhecem a presença de "um 'outro' da consciência que a condiciona, a influencia e a fundamenta" (p. 57). Entretanto, Deleuze enfatizou a distinção entre inconsciente ontológico e psicológico para formular "uma tese de cunho ontológico assentada numa espécie de 'passado-todo', contemporâneo do presente" (p. 57), e que, ao vir à consciência, "muda de natureza, transformando-se em lembrança de fato" (p. 57). Com essa tese, Deleuze, na esteira de Bergson, redimensionou "a noção de representação, situando-a como resultado do processo em que inconsciente e consciência relacionam-se indefinidamente" (p. 57).

Com uma prosa crítica livre de preciosismos e alheia a reduções conceituais simplistas, Débora Morato Pinto traça um panorama convincente da relação entre consciência e memória na Modernidade. Apesar dos limites intrínsecos aos livros introdutórios, a argumentação é bastante consistente e muito bem sustentada por exemplos esclarecedores. A edição cuidadosa ainda disponibiliza uma pequena coletânea com trechos de algumas das obras filosóficas que a 
autora comenta, bem como uma lista de sugestões de obras sobre consciência e memória e uma bibliografia comentada. Em conclusão, Consciência e memória, como sugere o nome da coleção da qual o livro faz parte, realmente provoca no leitor o prazer de pensar.

\section{Referências}

BERGSON, Henri (2006). A energia espiritual. Tradução de Rosemary C. Abílio. São Paulo: Martins Fontes.

BERGSON, Henri (1999). Matéria e memória. Tradução de Paulo Neves. São Paulo: Martins Fontes.

DELEUZE, Gilles (2006). Diferença e repetição. Tradução de Luiz Orlandi e Roberto Machado. Rio de Janeiro: Graal.

DELEUZE, Gilles (1999). Bergsonismo. Tradução de Luiz Orlandi. São Paulo: 34.

DESCARTES, René (2002). Princípios de filosofia. Vários autores. Rio de Janeiro: UFRJ.

HUME, David (2011). Tratado da natureza humana. Tradução de Déborah Danowski. São Paulo: Unesp. 